\title{
Video Article \\ Influence of Hybrid Perovskite Fabrication Methods on Film Formation, Electronic Structure, and Solar Cell Performance
}

\author{
Tobias Schnier ${ }^{1}$, Jennifer Emara ${ }^{1}$, Selina Olthof ${ }^{1}$, Klaus Meerholz ${ }^{1}$ \\ ${ }^{1}$ Department of Chemistry, University of Cologne \\ Correspondence to: Klaus Meerholz at klaus.meerholz@uni-koeln.de \\ URL: https://www.jove.com/video/55084 \\ DOI: doi:10.3791/55084
}

Keywords: Chemistry, Issue 120, perovskite, fabrication method, photoelectron spectroscopy, X-ray diffraction, solar cell

Date Published: 2/27/2017

Citation: Schnier, T., Emara, J., Olthof, S., Meerholz, K. Influence of Hybrid Perovskite Fabrication Methods on Film Formation, Electronic Structure, and Solar Cell Performance. J. Vis. Exp. (120), e55084, doi:10.3791/55084 (2017).

\section{Abstract}

Hybrid organic/inorganic halide perovskites have lately been a topic of great interest in the field of solar cell applications, with the potential to achieve device efficiencies exceeding other thin film device technologies. Yet, large variations in device efficiency and basic physical properties are reported. This is due to unintentional variations during film processing, which have not been sufficiently investigated so far. We therefore conducted an extensive study of the morphology and electronic structure of a large number of $\mathrm{CH}_{3} \mathrm{NH}_{3} \mathrm{Pbl}_{3}$ perovskite where we show how the preparation method as well as the mixing ratio of educts methylammonium iodide and lead(II) iodide impact properties like film formation, crystal structure, density of states, energy levels, and ultimately the solar cell performance.

\section{Video Link}

The video component of this article can be found at https://www.jove.com/video/55084/

\section{Introduction}

Thin film photovoltaic technologies have attracted a significant attention in the research of solar cell applications due to their low material consumption and applicability on flexible substrates. Most notably, organic/inorganic halide perovskite materials have proven to be viable active layers in solar cell devices, leading to high efficiencies. Perovskites feature advantageous properties such as high absorption coefficient ${ }^{1}$, high charge carrier mobility ${ }^{2}$, and low exciton binding energy ${ }^{3}$. Perovskite layers can be produced by various solution or vapor phase based fabrication methods using low cost precursor materials like lead(II) iodide ( $\left.\mathrm{Pbl}_{2}\right)$ and methylammonium iodide (MAI). This way allows for an easy preparation of high crystallinity films using low fabrication temperatures compared to the commercially available silicon solar cells.

It has been shown that several parameters have a strong influence on the performance of perovskite solar cells, most notably film morphology, as it influences exciton diffusion length and charge carrier mobility. Nie et al. showed that by improving the morphology of perovskite films, regarding the coverage and average crystal size, the solar cell performance increases ${ }^{4,5}$. The morphology has been shown to be influenced by (i) choice of precursor material (e.g. the use of lead acetate ${ }^{6}$ ), (ii) molecular additives (like $\left.\mathrm{NH}_{4} \mathrm{Cl}^{7}\right)^{7}$, (iii) choice of solvent, (iv) thermal annealing under solvent atmosphere (like toluene or chlorobenzene ${ }^{8}$ ), and particularly (v) the choice of preparation method ${ }^{9}$. Solution-based processes like one-step or two-step spin coating result in solar cells with efficiencies exceeding $17 \% \%^{4,10,11,12}$ whilst vacuum-deposited perovskite solar cells yield efficiencies of $15.4 \%{ }^{13}$.

It has been shown that excess $\mathrm{Pbl}_{2}$ in perovskite layers is advantageous for solar cell performance due to an improved carrier balance by passivation of the perovskite film by $\mathrm{Pbl}_{2}$ at the grain boundaries ${ }^{14}$. However, little work has been done to understand the role of the effects of stoichiometry on perovskite film materials.

In this paper we present an extensive study on a wide range of differently prepared perovskite films and show how the preparation methods and precursor stoichiometry influence the morphology, crystallinity, density of states, film composition, and solar cell performance. A holistic overview is presented, ranging from fabrication to film characterization all the way to device performance.

\section{Protocol}

\section{ITO Substrates}

NOTE: For an improved sample contacting and to avoid shorting of devices, the ITO coated glass substrates have to be patterned using lithography and etching. The overlap of top and bottom electrode defines the active area of the produced solar cells.

1. Cut the indium tin oxide (ITO) coated glass plate with a glass cutter to yield $2.5 \mathrm{~cm}$ by $2.5 \mathrm{~cm}$ substrates.

2. Glue a circular-shaped label (diameter $=1.6 \mathrm{~cm}$ ) in the center of an ITO covered substrate. 
3. Etch ITO by placing the substrates in a hydrochloric $1 \mathrm{M} \mathrm{FeCl}_{3}$ solution at $60{ }^{\circ} \mathrm{C}$ for $10 \mathrm{~min}$.

4. Clean the substrates sequentially with chloroform, acetone and soap solution (2\%) in an ultrasonic bath.

5. Rinse once more with distilled water and dry under $\mathrm{N}_{2}$ flow.

\section{Ozonation of the ITO Substrates}

NOTE: In order to remove organic impurities, the ITO substrates have to be ozonized. This activates the oxidic surface and increases the wetting properties of the substrate, which is crucial for the reproducible deposition of the subsequent layers.

1. Mount ITO substrates on a sample holder and place it in an ozonation chamber

2. Illuminate for 10 min under (atmospheric) oxygen with an ultraviolet lamp ( $20 \mathrm{~W})$ that generates ozone.

\section{Deposition of the PEDOT:PSS Hole-collecting Contact}

NOTE: A film of poly(3,4-ethylenedioxythiophene)-poly(styrenesulfonate) (PEDOT:PSS) is deposited by spin coating from an aqueous suspension under ambient conditions ( 25 to $40 \%$ relative humidity). This layer is used as a hole collecting contact and features a high work function, reduces pinholes, and leads to increased reproducibility of devices.

1. Place $150 \mu \mathrm{L}$ of the PEDOT:PSS in water suspension (1.5\%) with a syringe on the substrate after filtering through a $0.45 \mu \mathrm{m}$ filter.

2. Spin coat using a rotation speed of $2,500 \mathrm{rpm}$ for $25 \mathrm{~s}$ directly followed by $4,000 \mathrm{rpm}$ for $5 \mathrm{~s}$ with an acceleration of $4,000 \mathrm{rpm} / \mathrm{s}$ each. This procedure leads to 40 to $45 \mathrm{~nm}$ thick PEDOT:PSS films.

3. Remove residual water from the film by thermally annealing the substrates on a hotplate at $150{ }^{\circ} \mathrm{C}$ for $10 \mathrm{~min}$ in air.

\section{Deposition of the Perovskite Layers}

Caution: Lead iodide $\left(\mathrm{Pbl}_{2}\right)$ is highly toxic to humans. Even small amounts are extremely dangerous for the nervous, hematopoietic, renal, and hepatic systems. Handle lead containing solutions with care.

NOTE: The perovskite films investigated throughout this paper are prepared by five different methods using $\mathrm{Pbl}_{2}$ and $\mathrm{CH}_{3} \mathrm{NH}_{3} \mathrm{I}(\mathrm{MAl})$ as precursor materials. In order to avoid degradation ${ }^{15}$, fabrication of the films and devices and their characterization have to be performed under inert atmosphere, e.g. in a $\mathrm{N}_{2}$ filled glove box (solution processing) or under vacuum (vapor deposition).

\section{Solution processing}

1. Sequential deposition

1. Place substrate on spin coater and drop $150 \mu \mathrm{L} \mathrm{Pbl}$, dissolved in $\mathrm{N}, \mathrm{N}$-dimethylformamide, DMF (400 mg/mL) with a pipette on the substrate.

2. Spin coat immediately at $3,000 \mathrm{rpm}$ for $30 \mathrm{~s}$.

3. Dip $\mathrm{Pbl}_{2}$ films in MAI dissolved in isopropanol $(10 \mathrm{mg} / \mathrm{mL})$ for $40 \mathrm{~s}$ or drop $\mathrm{MAl}$ solution onto the dried $\mathrm{Pbl}_{2}$ film and leave there for $40 \mathrm{~s}$.

4. Spin coat remaining MAI solution at $3,000 \mathrm{rpm}$ for $30 \mathrm{~s}$ off the substrate.

5. Heat for $15 \mathrm{~min}$ at $100^{\circ} \mathrm{C}$ by placing the substrate on a hotplate.

2. Co-solution:

1. Dissolve both $\mathrm{Pbl}_{2}$ and MAI in the desired ratio (ideally $1: 1$ molar ratio) in DMF to form a precursor solution with a concentration of $250 \mathrm{mg} / \mathrm{mL}$.

2. Stir precursor solution at $50^{\circ} \mathrm{C}$ for at least $5 \mathrm{~h}$.

3. Preheat substrates covered with PEDOT:PSS at $50{ }^{\circ} \mathrm{C}$ for 5 min on a hotplate.

4. To guarantee an increased reproducibility throughout one device series, create a toluene atmosphere by dripping a small amount of the solvent $(200 \mu \mathrm{L})$ inside the spin coater bowl while spin coating the perovskite layer.

5. Place $150 \mu \mathrm{L}$ precursor solution (from 4.1.2.1) on the substrate.

6. Spin coat perovskite layers at 3,000 rpm for $30 \mathrm{~s}$ from this precursor solution. Spin coat one layer of perovskite material per substrate.

7. Heat the resulting perovskite layers for $30 \mathrm{~s}$ at $110^{\circ} \mathrm{C}$ on a hotplate.

3. Molecular Additive:

1. Co-dissolve $\mathrm{NH}_{4} \mathrm{Cl}(18-20 \mathrm{mg} / \mathrm{mL}$ ) in the spin coating solution (as described in 4.1.2.1) to ensure better film formation. Proceed as before.

NOTE: This is an alternative to the addition of the co-solution from 4.1.2.

\section{Vacuum deposition}

1. General procedure

1. Load the cleaned substrates into the vacuum system and evacuate.

2. After a pressure of $10^{-7} \mathrm{mbar}$ is reached, transfer samples into the evaporation chamber and shield it off from the evaporations sources with a shutter.

3. Heat the two sources that contain the precursor materials to approximately $330{ }^{\circ} \mathrm{C}$ for $\mathrm{Pbl}_{2}$ and $140{ }^{\circ} \mathrm{C}$ for $\mathrm{MAl}$. Be aware that the pressure in the chamber will rise to approximately $10^{-4} \mathrm{mbar}$ due to the volatile nature of the MAI.

4. Calibrate the evaporation rates for the two materials using one quartz crystal monitor (QCM) positioned close to the source while the other one is at the sample position. Heat the material to an evaporation temperature and simultaneously write down 
the respective thicknesses shown on both QCMs. Calculate the tooling factor by the ratio of the two values. For the thickness calculation use 6.16 and $1.23 \mathrm{~g} / \mathrm{cm}^{-3}$ for $\mathrm{Pbl}_{2}$ and $\mathrm{MAl}$, respectively.

2. Co-evaporation

1. Adjust the rates of $\mathrm{Pbl}_{2}$ to MAl to approximately $1: 2$ by increasing or decreasing the temperature of the sources to achieve a stoichiometrically correct perovskite film.

2. Open the shutter in front of the sample to start the deposition. After the intended thickness is reached, close the shutter and turn of the heating of the sources.

3. Heat the films for $1 \mathrm{~h}$ at $70{ }^{\circ} \mathrm{C}$ inside the vacuum chamber to remove volatile compounds and complete film formation.

3. Sequential evaporation

1. Reduce the temperature of the MAI source again below the point of evaporation (approx. $100{ }^{\circ} \mathrm{C}$ ) and heat up the $\mathrm{Pbl}_{2}$ source until the evaporation starts; deposit $50 \mathrm{~nm}$ of pure $\mathrm{Pbl}_{2}$.

2. Afterwards, cool down the $\mathrm{Pbl}_{2}$ source and evaporate $50 \mathrm{~nm}$ of MAl likewise. For larger thicknesses repeat steps 4.2 .3 .1 and 4.2.3.2 alternatively.

3. Heat the films for $1 \mathrm{~h}$ at $70^{\circ} \mathrm{C}$ inside the vacuum chamber to remove volatile compounds and complete film formation.

\section{Preparation of Solar Cells}

1. Dissolve the acceptor phenyl- $\mathrm{C}_{60}$-butyric acid methyl ester $\left(\mathrm{PC}_{60} \mathrm{BM}\right)$ in chlorobenzene at a concentration of $20 \mathrm{mg} / \mathrm{mL}$ and stir for at least one day on a hotplate at $50^{\circ} \mathrm{C}$.

2. Prepare the perovskite layer (co-solution process with additive) as shown before (see 4.1.3.).

3. Cool down the heated perovskite layers for $30 \mathrm{~s}$ on a metal plate to room temperature.

4. Place $150 \mu \mathrm{L}$ of $\mathrm{PC}_{60} \mathrm{BM}$ solution on the substrate

5. Spin coat $\mathrm{PC}_{60} \mathrm{BM}$ at $2,000 \mathrm{rpm}$ for $30 \mathrm{~s}$ on top of the perovskite film resulting in $50 \mathrm{~nm}$ thick layers.

6. Place fully coated substrates in a sample holder and cover with a shadow mask in order to evaporate contacts on top of the active layers.

7. Scratch one of the contacts with a scalpel in order to establish contact to the ITO anode.

8. Transfer into a vacuum chamber for the deposition of the cathode top contact.

9. Deposit $10 \mathrm{~nm}$ aluminum at a maximum pressure of $p=3 \times 10^{-6}$ mbar with a rate of $0.5 \AA / \mathrm{s}$, as measured by a quartz crystal monitor. After the first $10 \mathrm{~nm}$ the rate can be increased up to $2.5 \AA / \mathrm{s}$ until a layer thickness of $100 \mathrm{~nm}$ is reached.

10. Perform current density versus voltage (JV) measurements of the solar cells using a source measurement unit in the voltage range of -0.5 to $1.5 \mathrm{~V}$ (steps $=0.02 \mathrm{~V}$ ). To ensure that no hysteresis is appearing in the $\mathrm{JV}$ characteristics, measure the reverse scan direction as well, by sweeping the bias from 1.5 to $-0.5 \mathrm{~V}$ as well. Use a solar simulator $\left(100 \mathrm{~mW} \mathrm{~cm}^{2}\right)$ calibrated using a certified silicon photodiode.

\section{Representative Results}

In order to obtain a holistic view over the different fabrication methods for perovskite films, it is important to combine structural, electronic, and device characterization. Scanning electron microscopy (SEM) gives a good impression of morphology. Therefore, all films produced by the different fabrication methods were investigated. A representative subset of perovskite thin films is shown in Figure 1, which visualizes the significant influence of the preparation method on the film morphology.

Ideally, a smooth and pin-hole free film is desired for devices. As can be seen, this is the case for the vapor-deposited films ( $\mathrm{f}, \mathrm{g}$ ), the dip coated ones (d, e), and the films prepared from co-solution with the additive $\mathrm{NH}_{4} \mathrm{Cl}$ and toluene atmosphere (a1 to a5) with a varying ratio $\mathrm{R}$ of $\mathrm{Pbl}$ to MAI of 0.6 to 1.4. By contrast, the films without additive ( $h$ ), as well as the dip-coated (d, e) and drop-coated ones (b, c) show large voids, needle like structures, or large surface roughness and are therefore not useful for device applications. 


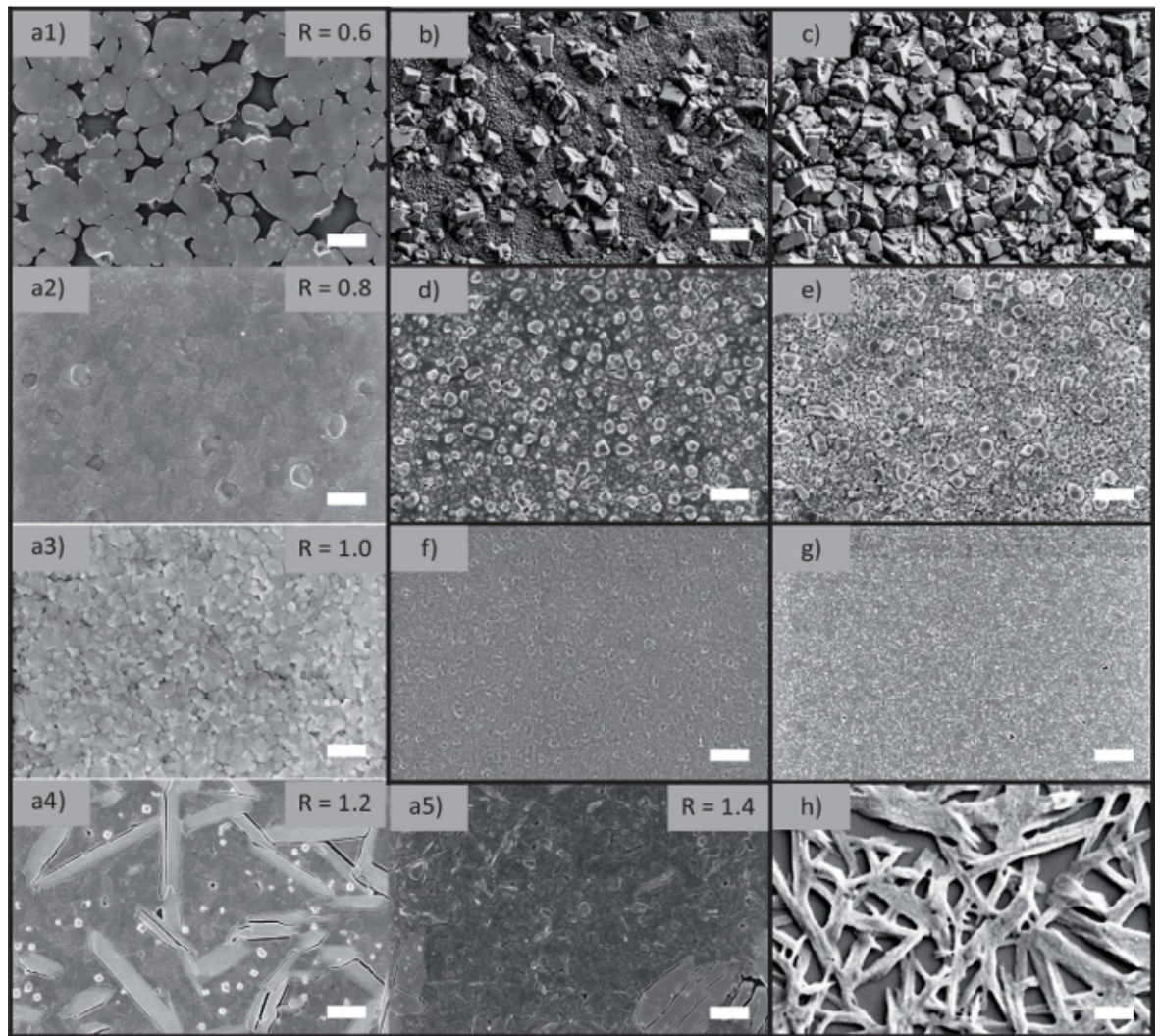

Figure 1: SEM images of perovskite films prepared by the different processing methods. (a1 - a5) Co-solution with additive and toluene atmosphere with different ratio of $\mathrm{Pbl}_{2}$ to $\mathrm{MAI}(\mathrm{R})$, (b) drop-coating with $40 \mathrm{~s}$ loading time, (c) drop-coating with $120 \mathrm{~s}$ loading time, (d) dip coating (10 s loading time), (e) dip coating (3,600 s loading time), (f) co-evaporation, (g) sequential evaporation, (h) co-solution without additive. The scale bars indicate a length of $1 \mu \mathrm{m}$. Please click here to view a larger version of this figure.

Finally, Figure $1 \mathrm{a} 1$-a5 show variations in mixing ratio $\mathrm{R}$ of $\mathrm{Pbl}_{2}$ to MAl from 0.6 to 1.4 using the co-solution preparation with additive and toluene atmosphere. The variations in surface coverage and crystal size show that here as well different film morphologies appear.

Although SEM is a good tool to visualize morphology and coverage of thin films and to get an impression on film roughness, however no structural information is given.

Therefore, in order to further characterize the perovskite films, X-ray diffraction (XRD) was used. With this technique using a Cu $\mathrm{K}_{\alpha}$ anode $(\lambda=1.54056 \AA)$ crystal phases in the range of $2 \theta$ between $10^{\circ}$ and $40^{\circ}$ (step size of $0.00836^{\circ}$ ) were monitored and characterized. In many publications XRD is used to determine the quality of perovskite films.

Figure 2 shows XRD measurements of a subset of samples having six different mixing ratios of $\mathrm{Pbl}_{2}$ to $\mathrm{MAl}$, and therefore corresponds to the SEM images in Figure 1a1-a5. In addition, the spectrum of pure $\mathrm{Pbl}_{2}$ is shown. From this, the influence of stoichiometry in the precursor solution on the quality of the perovskite layers, as such as the appearance of different phases, i.e. the incorporation of additional phases of $\mathrm{Pbl}_{2}$ and $\mathrm{MAI}$, is investigated. The spectra show a tetragonal crystal structure, and the reflections are indexed with their corresponding crystal planes. Surprisingly, no additional phases of $\mathrm{MAl}$ or $\mathrm{Pbl}_{2}$ were observed in the off-stoichiometric films.

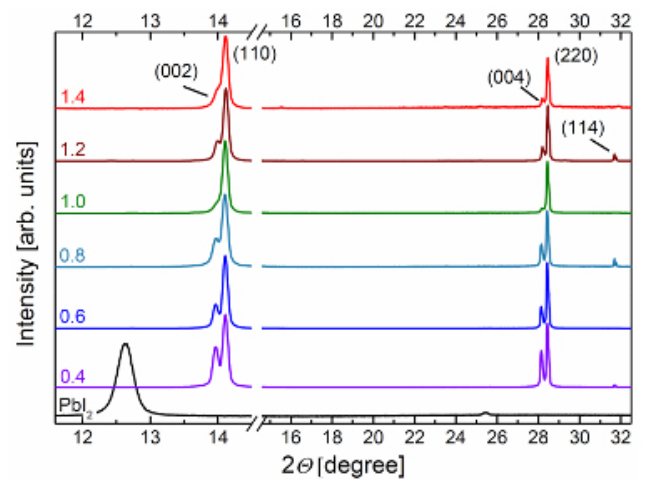

Figure 2: XRD pattern of pure $\mathrm{Pbl}_{2}$ as well as perovskite samples prepared by the co-solution method (with $\mathrm{NH}_{4} \mathrm{Cl}$ and toluene atmosphere) using various molar ratios of the precursors (ratios given by the numbers on the right). For comparability, the curves are 
normalized to the peak at $14.11^{\circ}$ and shifted vertically. Reprinted with permission from reference ${ }^{16}$. Copyright $2015 \mathrm{Wiley-VCH}$. Please click here to view a larger version of this figure.

As XRD did not provide information on the composition of the film, X-ray photoelectron spectroscopy (XPS) is used, which is able to directly measure film stoichiometry. For this measurement a $\mathrm{Mg} \mathrm{K}_{\alpha}$ excitation source $(\mathrm{hv}=1252.6 \mathrm{eV})$ with a pass energy of $10 \mathrm{eV}(\mathrm{Energy}$ resolution $=800 \mathrm{meV}$ ) is used. The relative sensitivity factors (RSF) must be taken into account for each individually measured element. As such, it is important to calibrate the RSFs for our measurement system $\left(\mathrm{Mg} \mathrm{K}_{\alpha}\right.$ source, angle between X-ray source and analyzer $\left.50.0^{\circ}\right)$. We used a number of small molecules to calibrate the iodine peak with Tris-(4-iodphenyl)-amine $\left(\mathrm{C}_{18} \mathrm{H}_{12} \mathrm{l}_{3} \mathrm{~N}\right)$, and calibrated $\mathrm{Pb}$ via $\mathrm{Pbl}$. Carbon is used as a reference, as such with an $\mathrm{RSF}(\mathrm{C} 1 \mathrm{~s})=1$, therefore, the $\mathrm{RSF}$ factors for the individual elements are; $\mathrm{RSF}(\mathrm{N} 1 \mathrm{~s})=1.8, \mathrm{RSF}\left(\mathrm{IJd}_{5 / 2}\right)=32.8$, and $\operatorname{RSF}\left(\mathrm{Pb}_{4} \mathrm{f}_{7 / 2}\right)=16.5$.

Figure 3 shows a representative XPS spectrum of a vapor deposited film, with the characteristic core level peaks indicated in upper sub-figure. In the lower subfigures $13 \mathrm{~d}_{5 / 2}(619.6 \mathrm{eV}), \mathrm{N} 1 \mathrm{~s}(402.7 \mathrm{eV}), \mathrm{C} 1 \mathrm{~s}(286.6 \mathrm{eV})$, and $\mathrm{Pb}_{7 / 2}(138.6 \mathrm{eV})$ peaks are shown. All signals can be fitted by a single mixed Gaussian/Lorentzian peak, only in the case of iodine a small feature at higher binding energies is typically observed which is however a shake-up peak and therefore not related to an actual additional bonding state. We are able to extract the relative film composition of all prepared perovskite layers by integrating over the signal intensity and normalizing it by their respective RSF ${ }^{16}$. In some of the films, large deviations were found from the ideal film stoichiometry $\mathrm{C}: \mathrm{N}: \mathrm{Pb}: \mathrm{I}$ of $1: 1: 1: 3 ;$ e.g. the lead to nitrogen ratio varied between 0.4 an $\mathrm{d} 1.5$. This was especially true for the vapor deposited films, where the co-evaporation is difficult to control and reproduce. For the solution processed samples, on the other hand, the actual and intended mixing ratios of the precursor agreed very well with the final film composition as determined from XPS.

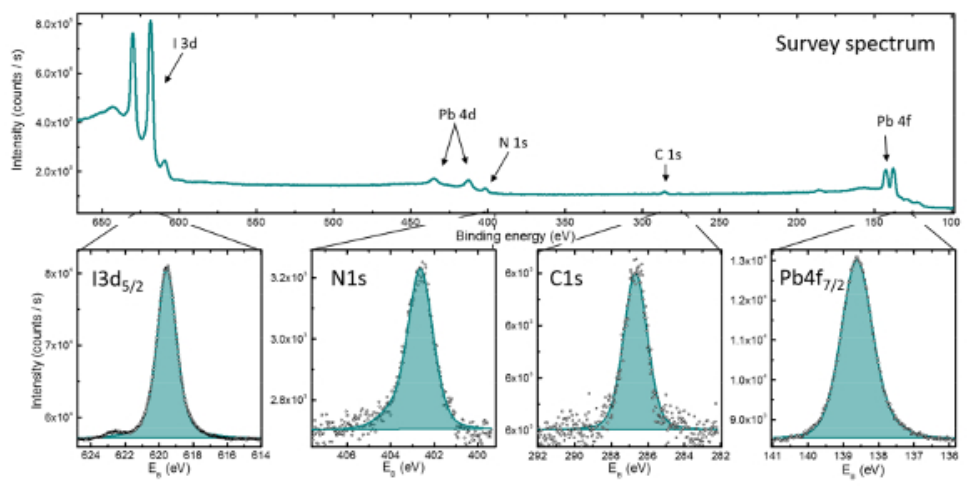

Figure 3: Representative XPS spectra. Above a full XPS scan is shown, below the close-up XPS measurements of the integrated peaks are shown. Please click here to view a larger version of this figure.

In order to investigate how these variations in film composition influence the density of states, we turned to UV photoelectron spectroscopy (UPS). To perform UPS measurements, a helium discharge lamp ( $\mathrm{He} \mathrm{I}$ at $21.22 \mathrm{eV}$, sample bias $-8 \mathrm{~V}$ ) is used, with a $2 \mathrm{eV}$ pass energy, and a $110 \mathrm{meV}$ energy resolution (as determined from the Fermi edge width). For all samples, a full spectrum was first measured, then using a higher analyzer aperture to increase the signal to noise ratio, a detailed higher resolution scan of the VB region was performed. In the UPS spectra, specifically the VB region scan, satellite peaks resulting from the polychromatic He I radiation were corrected for numerically during data analysis.

Figure 4 shows UPS curves of the complete dataset of all investigated samples, covering both co-and sequential evaporation (light red) as well as the different solution processing (dark red) methods. We only want to stress that significant variations in the ionization energies (IE) are observed, notable from the variations of the high binding energy cutoff position in the left hand plot of Figure 4. These changes are brought about by variations in processing and film composition and lead to a tunability of IE between 5.67 and $6.4 \mathrm{eV}$. For a more detailed discussion, refer to reference ${ }^{16}$.

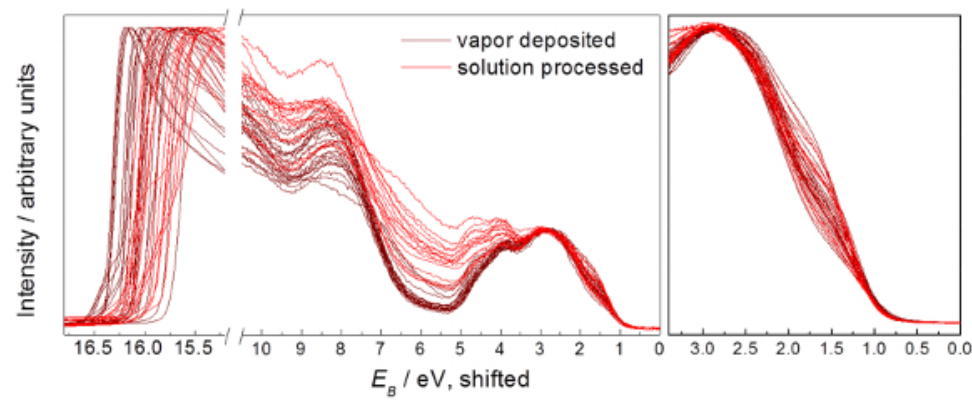

Figure 4: UPS scans of a representative subset of the investigated samples. The left panels show the high binding energy cutoff (HBEC) and the valence band region, while the right-hand side shows the high resolution close up of the VB onset for vapor-deposited (light red lines) and solution-processed (dark red lines) perovskite films. All curves have been shifted along the $\mathrm{x}$-axis in order to be aligned to the feature at around $3 \mathrm{eV}$. Reprinted with permission from reference ${ }^{16}$. Copyright 2015 Wiley-VCH. Please click here to view a larger version of this figure. 
As we learned from our previous experiments that perovskite films prepared from different precursor mixing ratios lead to variations in electronic structure without disrupting the crystal structure of the film, we wanted to investigate the effect of precursor ratio on the solar cell performance. Therefore, ITO/PEDOT:PSS/perovskite/PC ${ }_{60} \mathrm{BM} / \mathrm{Al}$ solar cells were prepared using co-solution processed perovskite layers (with additive and toluene atmosphere) using ratios of $\mathrm{Pbl}_{2}$ to $\mathrm{MAl}$ from 0.7 to 1.2. Figure $\mathbf{5}$ shows the impact of film stoichiometry (intended ratio R) on the solar cell characteristics power conversion efficiency (PCE), short-circuit current $\left(\mathrm{J}_{\mathrm{SC}}\right)$, open-circuit voltage $\left(\mathrm{V}_{\mathrm{OC}}\right)$ and fill factor (FF). The highest efficiency of $9.6 \%$ is found for an intended molar ratio of 1.02 , i.e. close to the ideal perovskite composition.

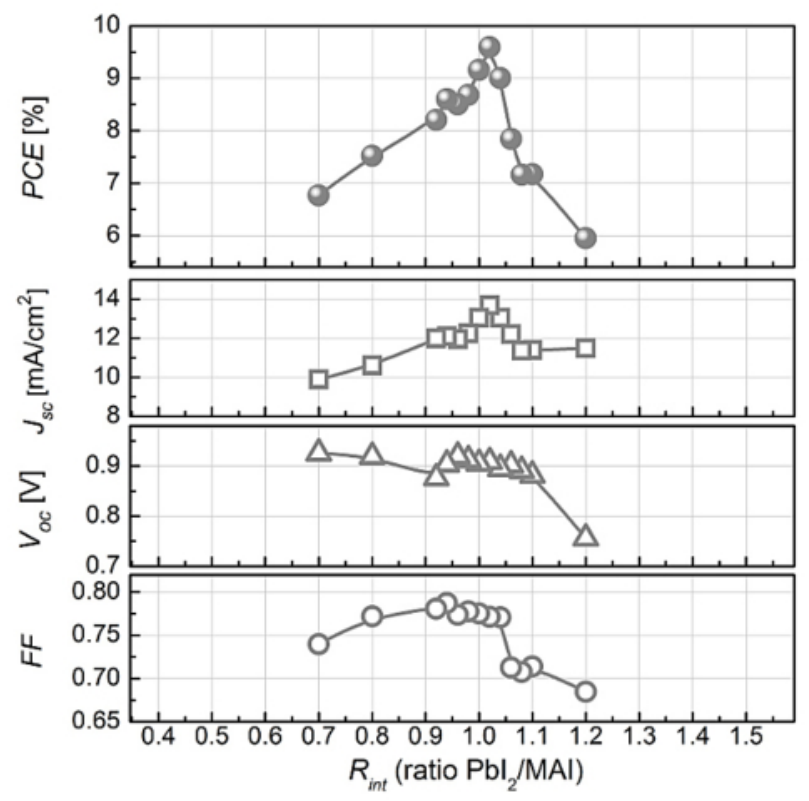

Figure 5: Characteristic values of PCE, $\mathbf{J}_{\mathbf{S C}}, \mathbf{V}_{\mathrm{OC}}$, and FF. These values were extracted from the measurements of the solar cell devices independent of the intended mixing ratio $\mathrm{R}_{\text {int }}$ of $\mathrm{Pbl}_{2}$ to MAl used for the film preparation. Reprinted with permission from reference ${ }^{16}$. Copyright 2015 Wiley-VCH. Please click here to view a larger version of this figure.

\section{Discussion}

We showed that the processing conditions have a significant influence on the film morphology and film coverage. This is the reason why a lot of research groups publish different results regarding solar cell performance and ionization potential for the same perovskite materials.

In order to ensure reproducibility, it is crucial for all the processing steps and characterization methods to be performed under inert atmosphere (or vacuum) to avoid degradation by humidity. Also the purity and vendor of the educts play an important role (not investigated herein). It is clear that vacuum deposited perovskite layers feature highly crystalline films; however, in comparison, solution processed films can be fabricated with a higher throughput.

In our study, using $\mathrm{NH}_{4} \mathrm{Cl}$ as an additive in the precursor solution and a toluene atmosphere in the spin coater bowl provided the most reproducible and smooth perovskite films. On the other hand, dip and drop coating processes lead to rather rough surfaces, and were not further considered for device application. Lastly, the vacuum processed layers feature overall smaller crystal sizes $(\sim 100 \mathrm{~nm})$ but with a high degree of coverage through the whole film and smoother surfaces. From the sample series with varying precursor ratio, we learned that the composition has a significant influence on film formation as well. However, when investigating these layers with XRD (Figure 2) all films show a high degree of crystallinity and a similar tetragonal crystal structure indicated by reflections at $14.11^{\circ}$ and $28.14^{\circ}$ representing the (110) and (220) planes, while some of the layers seemed slightly more disordered, which can be seen by the appearance of weak (002) and (004) reflections. However, no significant broadening of the XRD diffraction peak is observed. Intriguingly, no sign of separate phases of $\mathrm{Pbl}_{2}$ at $12.63^{\circ}$ are found, even for larger excess amounts of incorporated $\mathrm{Pbl}_{2}$. This indicates that $\mathrm{Pbl}_{2}$ is incorporated not as a separate phase or nanocrystalline islands but as dilute interstitials, which makes it undetectable by XRD. Thus, the use of XRD is limited.

On the other hand, XPS confirms that additional amounts of $\mathrm{Pbl}_{2}$ or MAI (depending on the fabrication method) are present in the film, as evident from the variations in the lead to nitrogen ratio. These interstitials in turn have a significant influence on the electronic structure of the film as mentioned before. Now, combining the findings from XPS with the observation of differences in ionization energies revealed by UPS enables us to correlate these two phenomena. Figure $\mathbf{6}$ shows the combined plot where the measured IE value is plotted as a function of the film composition (lead to nitrogen ratio) of the corresponding film. 


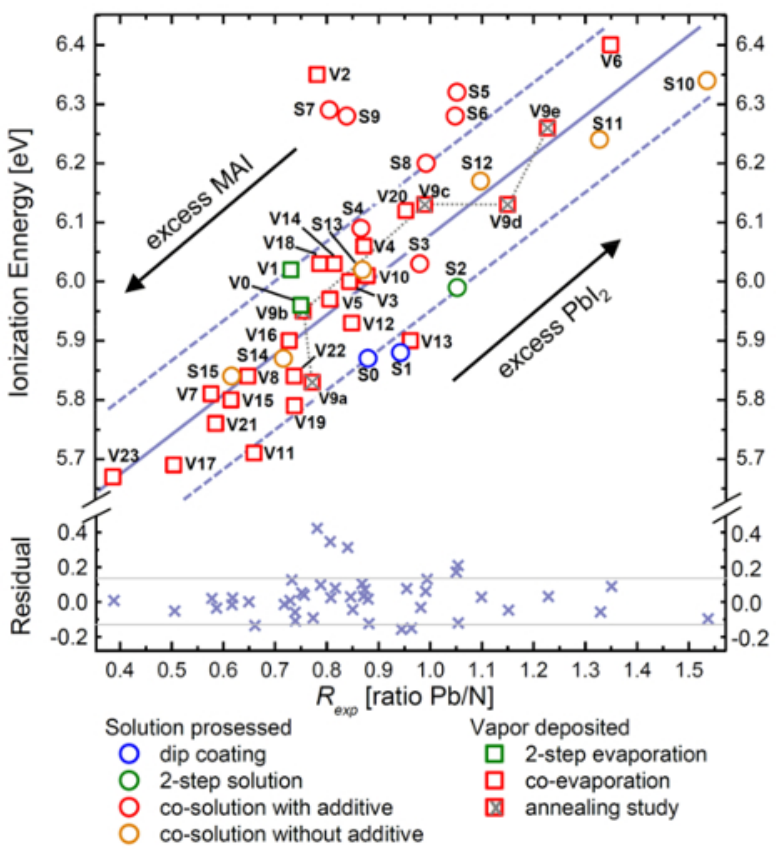

Figure 6: Extracted measurement points for the full data set of $\mathbf{4 0}$ perovskite films. Dependence of the ionization energy on the elemental ratio $R_{\text {exp }}$ of the lead to nitrogen content (as determined by XPS); the solid line is a linear fit to the data and the dashed lines mark the standard deviation of $\pm 0.12 \mathrm{eV}$. At the bottom, the residuals of the fit are shown. Reprinted with permission from reference ${ }^{16}$. Copyright $2015 \mathrm{Wiley}-\mathrm{VCH}$. Please click here to view a larger version of this figure.

We find a clear linear correlation between these two values. Our results, therefore, indicate that a perovskite film with MAI in excess exhibits a lower IE, while a $\mathrm{Pbl}_{2}$ rich layer increases the IE. We find an IE of $6.05 \pm 0.10 \mathrm{eV}$ for the optimal molar ratio of $R_{\exp }=1$, which is considerably larger than the often published IE of $5.4 \mathrm{eV}$. This discrepancy is not likely to be due to processing conditions, as we find this value for a variety of differently prepared perovskite films. It is rather due to differences in data evaluation where the linear density of states slope used here results in higher readout values. An extensive discussion of this issue can be found in reference ${ }^{17}$. It is important to note that we find no change in the optical bandgap of these films $\left(E_{g}=1.60 \pm 0.02 \mathrm{eV}\right.$, data not shown), which means that it is not only a shift of IE with varying ratio, but the activation energy (EA) shifts simultaneously.

The maximum solar cell efficiency was found for a molar ratio $\mathrm{R}$ of $1.02\left(\mathrm{Pbl}_{2}\right.$ to MAI) with a power conversion efficiency of $9.6 \%$ which confirms findings from literature ${ }^{14}$ that slightly $\mathrm{Pbl}_{2}$ rich films feature an improved carrier behavior by passivation of the perovskite film by $\mathrm{Pbl}_{2}$ at the grain boundaries. A decrease in open-circuit voltage by $200 \mathrm{meV}$ with increasing $\mathrm{Pbl}_{2}$ content can be found. Since no change in the bandgap of the perovskite material occurs, the decrease of $\mathrm{V}_{\mathrm{OC}}$ cannot be explained by a concurrent decrease of the photovoltaic gap but rather by insufficient hole blocking at the interface of perovskite and PCBM $\left(\mathrm{IE}_{\mathrm{PCBM}}=6.2 \mathrm{eV}\right)$ due to the increase in perovskite IE. Simultaneously the FF for R $>1.05$ decreases from 0.8 to 0.7 which supports these findings.

In conclusion, we presented an extensive study of perovskite films made by a variety of preparation methods and found that strong variations occur in film formation, electronic structure and device performance. Of particular interest is the possibility to adjust IE of perovskite by intentional incorporation of $\mathrm{MAl}$ or $\mathrm{Pbl}_{2}$ interstitials which can be used for interface optimization in novel device architectures. Future studies will look at more advanced preparation techniques that aim towards larger device areas. These include methods like doctor blading, spray techniques, and large scale printing that are currently installed in our facility at the COPT.centre (COPT = center for organic production technologies).

\section{Disclosures}

The authors have nothing to disclose.

\section{Acknowledgements}

The authors would like to acknowledge financial support by the state of North Rhine-Westphalia through the project PERO-BOOST (EFRE, project code NW-1-1-040a). Thanks go to Azar Jahanbakhsh and Ines Schmidt (both University of Cologne) for assistance with fabrication and characterization of the 2-step solution processed perovskite layers, Dr. Jürgen Schelter (University of Cologne) for the synthesis of the MAI material as well as Prof. Dr. Riedl and Neda Pourdavoud (both University of Wuppertal) for the XRD measurements.

\section{References}

1. Green, M. A., Ho-Baillie, A., \& Snaith, H. J. The emergence of perovskite solar cells. Nat. Photonics. 8, 506-514 (2014). 
2. Stoumpos, C. C., Malliakas, C. D., \& Kanatzidis, M. G. Semiconducting Tin and Lead lodide Perovskites with Organic Cations: Phase Transitions, High Mobilities, and Near-Infrared Photoluminescent Properties. Inorg. Chem. 52, 9019-9038 (2013).

3. Saba, M., et al. Correlated electron-hole plasma in organometal perovskites. Nat. commun. 5, 5049 (2014).

4. Nie, W., et al. High-efficiency solution-processed perovskite solar cells with millimeter-scale grains. Science. 347, $522-525$ (2015).

5. Eperon, G. E., Burlakov, V. M., Docampo, P., Goriely, A., \& Snaith, H. J. Morphological Control for High Performance, Solution-Processed Planar Heterojunction Perovskite Solar Cells. Adv. Funct. Mater. 24, 151-157 (2014).

6. Li, C., et al. Efficient lead acetate sourced planar heterojunction perovskite solar cells with enhanced substrate coverage via one-step spincoating. Org. Electron. 33, 194-200 (2016).

7. Zuo, C., \& Ding, L. An $80.11 \%$ FF record achieved for perovskite solar cells by using the $\mathrm{NH} 4 \mathrm{Cl}$ additive. Nanoscale. 6, 9935-9938 (2014)

8. Henawey, M. I., Gebhardt, R., El-Tonsy, M. M., \& Chaudhary, S. Organic solvent vapor treatment of the lead iodide layer in the two-step sequential deposition of $\mathrm{CH} 3 \mathrm{NH} 3 \mathrm{Pbl}$-based perovskite solar cells. J. Mater. Chem. A. (2015).

9. Yang, L., Barrows, A. T., Lidzey, D. G., \& Wang, T. Recent progress and challenges of organometal halide perovskite solar cells. Reports Prog. Phys. 79.026501 (2016).

10. Jeon, N. J., et al. Compositional engineering of perovskite materials for high-performance solar cells. Nature. (2015).

11. Im, S. H., Heo, J.-H., Han, H. J., Kim, D., \& Ahn, T. 18.1 \% hysteresis-less inverted CH3NH3Pbl3 planar perovskite hybrid solar cells. Energy Environ. Sci. (2015).

12. Kim, B.-S., Choi, M.-H., Choi, M.-S., \& Kim, J.-J. Composition-controlled organometal halide perovskite via $\mathrm{CH} 3 \mathrm{NH} 3 \mathrm{I}$ pressure in vacuum co-deposition process. J. Mater. Chem. A. 4, 5663-5668 (2016).

13. Liu, M., Johnston, M. B., \& Snaith, H. J. Efficient planar heterojunction perovskite solar cells by vapour deposition. Nature. 501, 395-8 (2013).

14. Chen, Q., Zhou, H. P., et al. Controllable Self-Induced Passivation of Hybrid Lead lodide Perovskites toward High Performance Solar Cells. Nano Lett. 14, 4158-4163 (2014).

15. Yamamoto, K., et al. Degradation mechanism for planar heterojunction perovskite solar cells. Jpn. J. Appl. Phys. 07 (2016).

16. Emara, J., et al. Impact of Film Stoichiometry on the Ionization Energy and Electronic Structure of CH3NH3Pbl3 Perovskites. Adv. Mater. 28, 553-559 (2016).

17. Olthof, S. The electronic structure of hybrid perovskite layers and their energetic alignment in devices. APL Mater. 4, 091502 (2016). 